\title{
Direct application of supercritical carbon dioxide for the reduction of Cronobacter spp. (Enterobacter sakazakii) in end products of dehydrated powdered infant formula
}

\author{
S. A. Kim, O. Y. Kim, ${ }^{1}$ and M. S. Rhee ${ }^{2}$ \\ Division of Food Bioscience and Technology, College of Life Sciences and Biotechnology, Korea University, Seoul 136-713, South Korea
}

\begin{abstract}
The objective of this study was to develop a viable new method for inactivation of Cronobacter spp. that could be applied directly to dehydrated powdered infant formula (PIF) using supercritical carbon dioxide $\left(\mathrm{SC}-\mathrm{CO}_{2}\right)$. Samples inoculated with Cronobacter spp. were subjected to $\mathrm{SC}-\mathrm{CO}_{2}$ treatment under various conditions (temperature: 63,68 , and $73^{\circ} \mathrm{C}$; pressure: 15, 20, and $25 \mathrm{MPa}$; time: 10, 20, and $30 \mathrm{~min})$. The survival of Cronobacter spp. was assayed, as were any changes in the quality of the treated PIF. Inactivation of Cronobacter spp. by $\mathrm{SC}-\mathrm{CO}_{2}$ was enhanced as temperature and pressure conditions increased $(>6.32$ $\left.\log _{10} \mathrm{cfu} / \mathrm{g}\right)$. In a validation assay using low-level inoculation $\left(3.21 \log _{10} \mathrm{cfu} / \mathrm{g}\right)$, treatment at $73^{\circ} \mathrm{C}$ and $15 \mathrm{MPa}$ for $30 \mathrm{~min}, 20 \mathrm{MPa}$ for 20 and $30 \mathrm{~min}$, or $25 \mathrm{MPa}$ for 20 and 30 min reduced Cronobacter spp. to undetectable levels, with no recovery of cell viability. There was no significant change in water activity, $\mathrm{pH}$, and color of the treated PIF. Overall, the optimum conditions for elimination of Cronobacter spp. were determined to be $73^{\circ} \mathrm{C}$ and $20 \mathrm{MPa}$ for $20 \mathrm{~min}$. These parameters for effective $\mathrm{SC}-\mathrm{CO}_{2}$ treatment are feasibly applicable to end product of dehydrated PIF. The results of our study may contribute to the development of an efficient method for improving the microbiological safety of PIF.
\end{abstract}

Key words: Cronobacter spp., dehydrated powdered infant formula, supercritical carbon dioxide, inactivation

\section{INTRODUCTION}

Enterobacter sakazakii, recently reclassified into 6 new species in a new genus, Cronobacter (Iversen et al., 2007), has been implicated in infections of neonates

\footnotetext{
Received September 16, 2009.

Accepted January 13, 2010.

${ }^{1}$ Present address: Research \& Development Center, Korea Yakult Co. Ltd., Youngin 446-901, South Korea.

${ }^{2}$ Corresponding author: rheems@korea.ac.kr
}

and infants, who are easily susceptible to foodborne pathogens because of their weak immune systems. The primary source of infection has been reported to be reconstituted powdered infant formula and powdered milk, which are a main source of nutrition for neonates and infants (Simmons et al., 1989; van Acker et al., 2001; Centers for Disease Control and Prevention, 2002; Weir, 2002). Cronobacter spp. is considered an opportunistic pathogen that is associated with a variety of clinical manifestations, including fatal neonatal meningitis, sepsis, and necrotizing enterocolitis (Muytjens et al., 1983; Gallagher and Ball, 1991; Burdette and Santos, 2000; Bar-Oz et al., 2001). Because of their ability to survive in dry conditions, as in powdered infant formula (Edelson-Mammel et al., 2005; Barron and Forsythe, 2007), elimination of Cronobacter spp. from food sources is of great concern of the dairy industry.

The primary means of pasteurization and sterilization in the production of powdered infant formula (PIF) is thermal inactivation of microorganisms. Despite attempts to control Cronobacter spp. contamination in products, thermal treatments cannot be efficiently applied to solid products because of their low thermal conductivity. Cronobacter spp. has been isolated from end products that had been subjected to thermal treatment during production. Additionally, the use of heat for inactivation of bacteria results in denaturation of proteins as well as changes in physical, mechanical, and optical properties of the food products (Dempsey and Thirucote, 1989; Nair, 1995; König et al., 1997; Spilimbergo et al., 2003). Therefore, it is essential to develop new interventions applicable to end products in powdered form to minimize the probability of posttreatment contamination and to maintain the natural appearance and the quality of the formula.

The use of supercritical carbon dioxide $\left(\mathbf{S C}-\mathbf{C O}_{2}\right)$ has become an attractive nonthermal method for inactivation of bacteria (Kim et al., 2007b). Supercritical $\mathrm{CO}_{2}$ existing beyond a critical point $(7.38 \mathrm{MPa}$ and $31.1^{\circ} \mathrm{C}$ ) is commonly used for extraction purposes. Since Kamihira et al. (1987) first applied $\mathrm{SC}-\mathrm{CO}_{2}$ to inactivate microorganisms, including Escherichia coli, Staphylococcus aureus, and conidia of Aspergillus niger, 
many researchers have reported the successful application of $\mathrm{SC}-\mathrm{CO}_{2}$ to control microorganisms and spores in physiological saline and various food products (Enomoto et al., 1997; Hong et al., 1997; Mazzoni et al., 2001; Spilimbergo and Bertucco, 2003; Bae et al., 2009; Choi et al., 2009). Inactivation of microorganisms by $\mathrm{SC}-\mathrm{CO}_{2}$ can be achieved under relatively mild processing conditions compared with other treatments because treatment with $\mathrm{SC}-\mathrm{CO}_{2}$ affects bacterial survival both physically and chemically (Kim et al., 2007b). These mild conditions of $\mathrm{SC}-\mathrm{CO}_{2}$ allow for effective decontamination of microorganisms with minimal changes in product properties.

To date, the viability of direct application of $\mathrm{SC}-\mathrm{CO}_{2}$ to dehydrated PIF for the elimination of Cronobacter spp. has not been researched. The present study was designed to investigate the optimal conditions for SC$\mathrm{CO}_{2}$ application (temperature, pressure, and exposure time) that both effectively inactivates Cronobacter spp. and maintains the innate properties (water activity, $\mathrm{pH}$, and color) of dehydrated PIF.

\section{MATERIALS AND METHODS}

\section{Test Organisms}

Three strains of Cronobacter spp. (previously Enterobacter sakazakii; ATCC 12868, 29004, and 29544) used in this study were obtained from the Food Microbiology Culture Collection at Korea University (Seoul, Korea) and were maintained on tryptic soy agar (Difco, Sparks, MD) slants at $4^{\circ} \mathrm{C}$ and subcultured at monthly intervals. Each strain of Cronobacter spp. was cultured separately twice in $10 \mathrm{~mL}$ of Enterobacteriaceae enrichment broth (Difco) in screw-cap tubes at $37^{\circ} \mathrm{C}$ for $24 \mathrm{~h}$ before use in experiments. The enrichment cultures of each strain were combined in plastic $50-\mathrm{mL}$ centrifuge tubes (Becton Dickinson, Franklin Lakes, NJ) and cells were harvested by centrifugation (Centra-CL2, IEC, Needham Heights, MA) at 2,600 $\times g$ for $15 \mathrm{~min}$. After the supernatant was discarded, the pellets were washed twice with $0.85 \%$ sterile saline. The final pellets were resuspended in $0.85 \%$ sterile saline.

\section{Sample Preparation and Inoculation}

The commercial milk-based powdered infant formula (Maeil Co. Ltd., Pyungteck, Korea) was purchased from a local market. After the sample was spread on aluminum foil placed on a laminar flow clean bench, cocktailed cultures were sprayed vertically onto the sample, yielding an initial population of approximately $10^{6}$ to $10^{7} \mathrm{cfu} / \mathrm{g}$. The samples were mixed thoroughly using a sterile spatula and then dried at ambient temperature for $48 \mathrm{~h}$ in the clean bench. The water activity of noninoculated and inoculated PIF was measured using the Thermoconstanter TH200 (Novasina, Lachen, Switzerland), and no difference was detected (data not shown). Ten grams of sample inoculated with Cronobacter spp. were transferred into a sterile conical tube for $\mathrm{SC}-\mathrm{CO}_{2}$ treatment. An equal portion of the inoculated sample (10 g) was also taken as a control for initial cell counting.

\section{Supercritical Carbon Dioxide and Heat Treatment}

The schematic diagram of the supercritical carbon dioxide system used (Supercritical $\mathrm{CO}_{2}$ Gas Extractor, Ilshin Engineering, Seoul, Korea) is shown in Figure 1. When the extractor reached the desired temperature, the $10 \mathrm{~g}$ of sample in the conical tube was put into the vessel and sealed. Carbon dioxide with $99.5 \%$ purity was injected into the extractor using a $\mathrm{CO}_{2}$ gas pump. The valve was locked when the designated pressure was reached and the $\mathrm{SC}-\mathrm{CO}_{2}$ treatment was performed. After treatment was completed, the vessel was depressurized. The $\mathrm{CO}_{2}$ was completely removed from the extractor, the sample was retrieved, and viable cell counts were determined. Treatment conditions were set above the critical parameters for $\mathrm{CO}_{2}\left(31.1^{\circ} \mathrm{C}\right.$ and $7.38 \mathrm{MPa}$ ) based on the results from a preliminary experiment. The temperature was set at either 63,68 , or $73^{\circ} \mathrm{C}$, based on the treatment temperature of raw milk, which ranges from $63^{\circ} \mathrm{C}$ (pasteurization) to $73^{\circ} \mathrm{C}$ (high temperature sterilization). The pressure was examined at 15,20 , and $25 \mathrm{MPa}$, with the maximum pressure of the $\mathrm{SC}-\mathrm{CO}_{2}$ system being $30 \mathrm{MPa}$. The inactivation effects of $\mathrm{SC}-\mathrm{CO}_{2}$ on Cronobacter spp. were compared with heat treatments alone. The $10 \mathrm{~g}$ of PIF inoculated with Cronobacter spp. in the conical tube was treated with the same temperatures and times of $\mathrm{SC}-\mathrm{CO}_{2}$. The heated samples were immediately cooled in an ice-water bath for $1 \mathrm{~min}$. Both $\mathrm{SC}-\mathrm{CO}_{2}$ and heat treatments were performed in triplicate.

\section{Enumeration of Survivors}

Surviving bacteria were enumerated using a spreadplating method. Samples (10 g) were placed in stomacher bags containing $90 \mathrm{~mL}$ of $0.2 \%$ sterile peptone water and homogenized for $2 \mathrm{~min}$ with a stomacher (400 Circulator, Seward, London, UK). One milliliter of sample was serially diluted to $10^{-6}$ with $9 \mathrm{~mL}$ of $0.2 \%$ sterile peptone water. One hundred microliters of each diluent $\left(10^{-1}, 10^{-2}, 10^{-3}, 10^{-4}, 10^{-5}\right.$, and $\left.10^{-6}\right)$ was spread-plated on 2 Chromogenic Enterobacter sakazakii agar (DFI Formulation, Oxoid, Hampshire, UK) plates. For lower detection limit (10 cfu/g), $200 \mu \mathrm{L}$ of 10-fold 


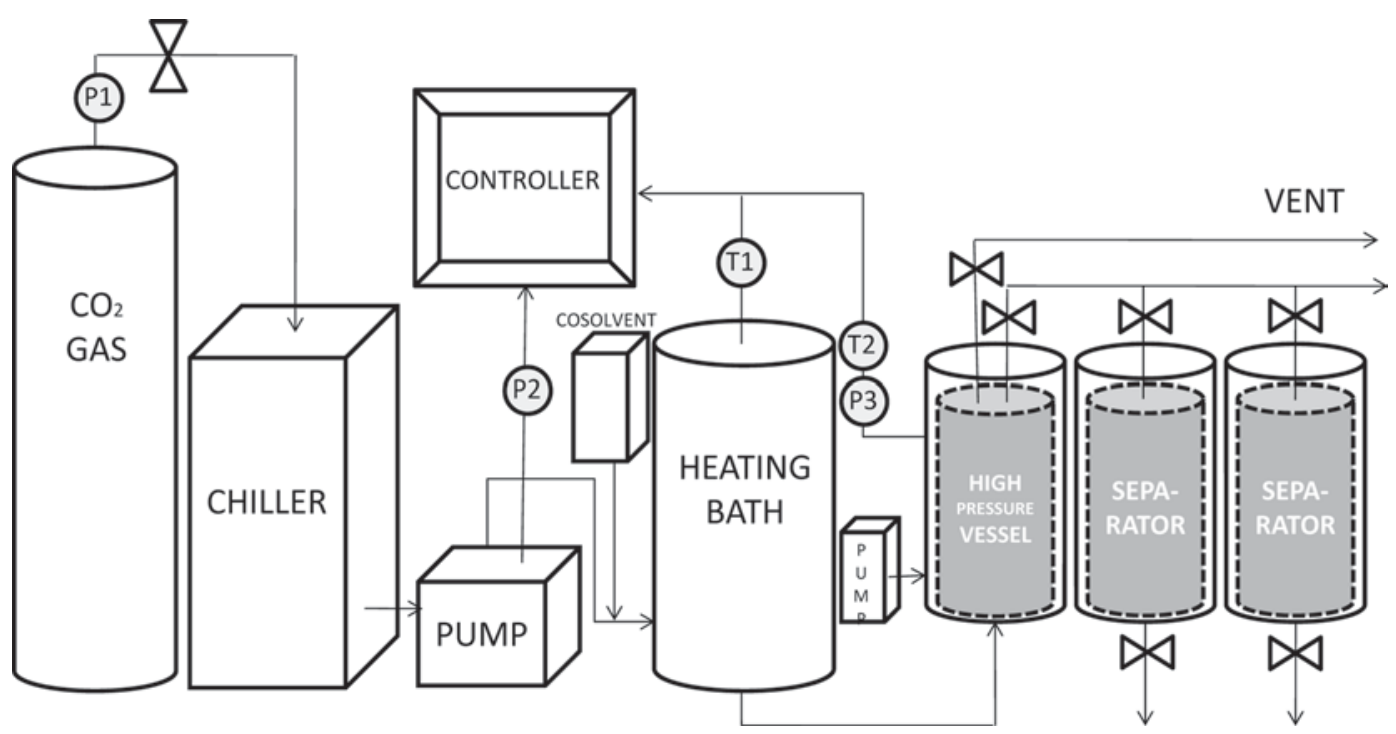

Figure 1. The supercritical carbon dioxide system. P1, P2, and P3 indicate the outlet of the $\mathrm{CO}_{2}$ cylinder, the inlet, and the vessel pressure, respectively. T1 and $\mathrm{T} 2$ indicate inlet and vessel temperature, respectively.

diluents $\left(10^{-1}\right)$ was spread-plated on 5 plates. The plates were incubated at $37^{\circ} \mathrm{C}$ for $24 \mathrm{~h}$ and then cells were enumerated by counting blue-green colonies. In the case of samples expected to have a population of $<10 \mathrm{cfu} / \mathrm{g}, 10 \mathrm{~g}$ of each sample was diluted with $10 \mathrm{~mL}$ of $0.2 \%$ sterile peptone water to obtain 2 -fold diluted samples. After homogenization, $200 \mu \mathrm{L}$ of the 2 -fold diluted samples were spread-plated on 10 Chromogenic Enterobacter sakazakii agar plates (detection limit: 1 $\mathrm{cfu} / \mathrm{g})$.

\section{Validation Assay}

For the validation assay, the inactivation effects of $\mathrm{SC}-\mathrm{CO}_{2}$ were examined following inoculation of PIF with a low level of Cronobacter spp. and the extent of recovery of injured cells was investigated. The cocktail cultures were inoculated into dehydrated PIF by the method described above, yielding an initial population of approximately $10^{3}$ to $10^{4} \mathrm{cfu} / \mathrm{g}$. After $\mathrm{SC}-\mathrm{CO}_{2}$ treatment, $10 \mathrm{~g}$ of each undiluted sample was transferred into $90 \mathrm{~mL}$ of Enterobacteriaceae enrichment broth and incubated at $37^{\circ} \mathrm{C}$ for $24 \mathrm{~h}$. Enriched samples were streaked with a flamed loop onto Chromogenic Enterobacter sakazakii agar. The experiments were performed in triplicate and the results were recorded as either positive or negative.

\section{Changes in Water Activity, $\mathrm{pH}$, and Color}

The water activity of PIF before and after $\mathrm{SC}-\mathrm{CO}_{2}$ treatment was measured using the Thermoconstanter TH200 at room temperature. The $\mathrm{pH}$ of samples hy- drated with sterile distilled water was determined with a combination electrode (MP220 basic, Mettler-Toledo, Greifensee, Switzerland) before and after treatment.

Samples of treated PIF were examined for changes in color stability. The surface color of dehydrated PIF was measured with a chromameter (CR-300, Minolta Camera Co., Osaka, Japan) calibrated against a white tile $(\mathrm{C}: \mathrm{Y}=91.7, \mathrm{x}=0.3138, \mathrm{y}=0.3200)$. The values were expressed as Commission International de l'Eclairage (CIE) $L^{*}$ (luminosity or lightness: $-L^{*}=0$ black and $+L^{*}=100$ white), $a^{*}$ (green-red component: $-a^{*}=$ greenness and $+a^{*}=$ redness), and $b^{*}$ (blue-yellow component: $-b^{*}=$ blueness and $+b^{*}=$ yellowness). The color change values $\left(\Delta \mathbf{E}^{*}\right)$ were calculated as

$$
\Delta \mathrm{E}^{*}=\sqrt{\left(\Delta L^{*}\right)^{2}+\left(\Delta a^{*}\right)^{2}+\left(\Delta b^{*}\right)^{2}},
$$

where $\Delta$ indicates the difference between the measured colors of the control and experimental treatment.

\section{Statistical Analysis}

The duplicate plate counts averages for the 3 replications were converted to $\log _{10}$ colony-forming units per gram for ANOVA. Analyses were performed with the general linear model procedure of SAS (version 8.2, SAS Institute Inc., Cary, NC). The model was $y_{i j k}=\mu$ $+T_{i}+B_{j}+M_{k}+e_{i j k}$, where $y_{i j k}$ is the observation; $\mu$ is the general mean; $T_{i}$ is the fixed effect of the treatment temperature $i ; B_{j}$ is the fixed effect of pressure $j ; M_{k}$ is the fixed effect of time $k$; and $e_{i j k}$ is the random error. 


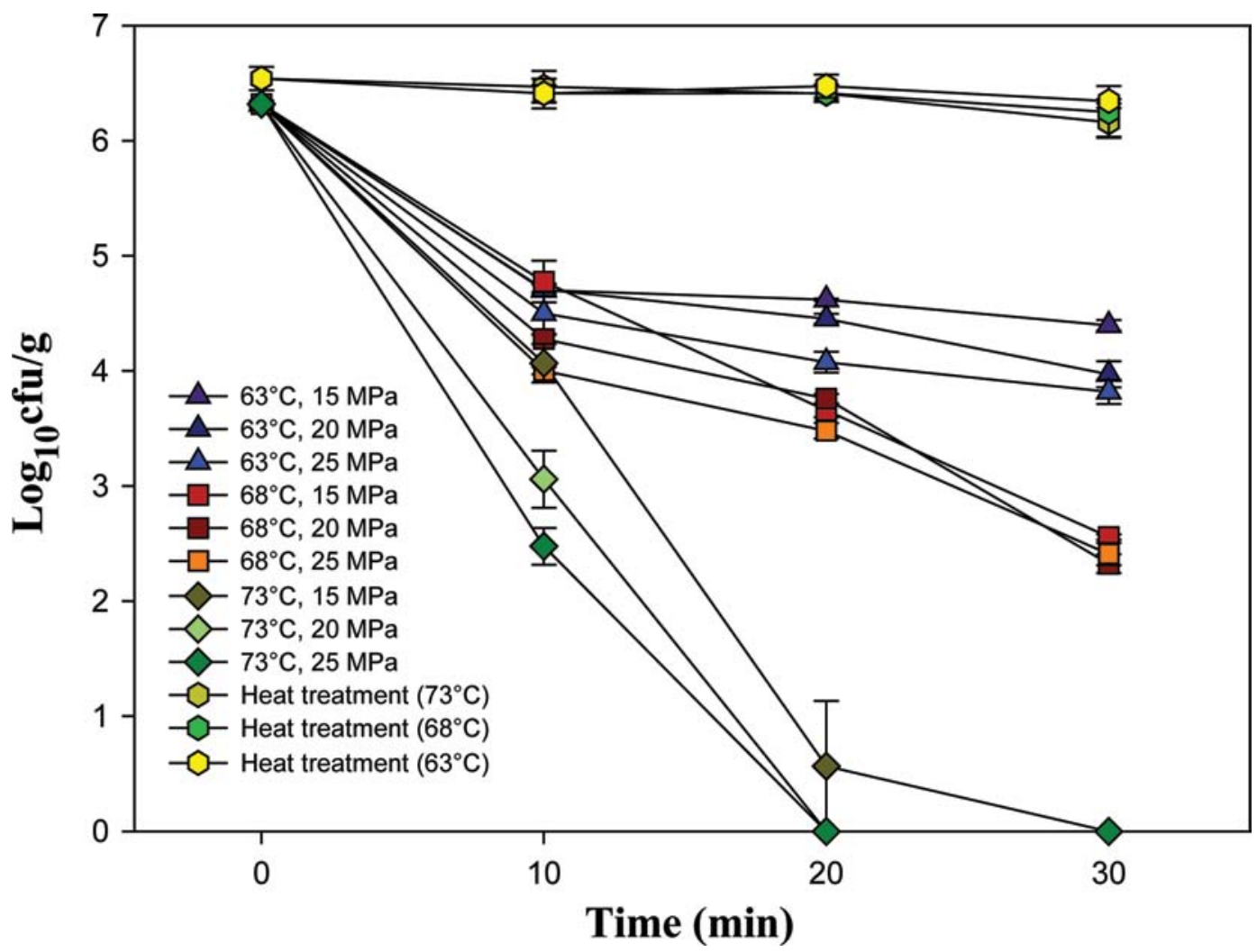

Figure 2. The antimicrobial effects of supercritical carbon dioxide and heat treatment on Cronobacter spp. in powdered infant formula $(\mathrm{n}=$ 3) under various conditions. T-bars indicate standard errors. Color version available in online PDF.

When the ANOVA indicated significant differences, least squares means were separated by the probability option (PDIFF, a pairwise $t$-test).

\section{RESULTS AND DISCUSSION}

\section{Antimicrobial Effects of SC- $\mathrm{CO}_{2}$ Treatment and Heat Treatment on Cronobacter spp.}

Figure 2 shows the antimicrobial effects of $\mathrm{SC}-\mathrm{CO}_{2}$ and heat treatment on Cronobacter spp. in dehydrated PIF under various conditions. Heat treatment at 63 , 68 , or $73^{\circ} \mathrm{C}$ did not affect the population of Cronobacter spp. $(P>0.05)$; these results indicate that heat treatment alone is insufficient to inactivate Cronobacter spp. in dehydrated PIF. When the samples were exposed to $\mathrm{SC}-\mathrm{CO}_{2}$ at $63^{\circ} \mathrm{C}$, the reduction in Cronobacter spp. ranged from $1.61 \log _{10} \mathrm{cfu} / \mathrm{g}$ (at $20 \mathrm{MPa}$ for $10 \mathrm{~min}$ ) to $2.50 \log _{10} \mathrm{cfu} / \mathrm{g}$ (at $25 \mathrm{MPa}$ for $30 \mathrm{~min}$ ). At $63^{\circ} \mathrm{C}$, Cronobacter spp. was rapidly reduced within $10 \mathrm{~min}$ of treatment, but then reached a plateau from 10 to $30 \mathrm{~min}$. On the other hand, the levels of inactivation gradually increased over a given treatment time at 68 and $73^{\circ} \mathrm{C}$. At $68^{\circ} \mathrm{C}$, the degree of reduction continued to increase with treatment time, and reductions in Cronobacter spp. levels from $1.54 \log _{10} \mathrm{cfu} / \mathrm{g}\left(68^{\circ} \mathrm{C}\right.$ at 15 $\mathrm{MPa}$ for $10 \mathrm{~min})$ to $3.99 \log _{10} \mathrm{cfu} / \mathrm{g}\left(68^{\circ} \mathrm{C}\right.$ at $20 \mathrm{MPa}$ for $30 \mathrm{~min}$ ) were achieved during the time course. At $73^{\circ} \mathrm{C}$, a reduction of more than $2.25 \log _{10} \mathrm{cfu} / \mathrm{g}$ was observed at $15 \mathrm{MPa}$ for $10 \mathrm{~min}$, and treatment with $15 \mathrm{MPa}$ for $30 \mathrm{~min}, 20 \mathrm{MPa}$ for $30 \mathrm{~min}, 25 \mathrm{MPa}$ for $30 \mathrm{~min}, 20 \mathrm{MPa}$ for $20 \mathrm{~min}$, and $25 \mathrm{MPa}$ for $20 \mathrm{~min}$ reduced the number of Cronobacter spp. to undetectable levels.

For any given combination of treatment conditions, a significant reduction $(P<0.001)$ in the amount of Cronobacter spp. was achieved. The effectiveness of inactivation by $\mathrm{SC}-\mathrm{CO}_{2}$ is enhanced by increases in temperature, pressure, and time.

The inactivation action of highly pressurized $\mathrm{CO}_{2}$ can be attributed to a variety of cellular effects, such as cell membrane modification, enzyme inactivation and metabolism inhibition because of a reduction in cytosolic $\mathrm{pH}$, the effect of $\mathrm{CO}_{2}$ and $\mathrm{HCO}_{3}{ }^{-}$on cellular metabolism, destruction of the intracellular electrolyte balance, and the extraction of vital constituents of cells and membranes (Garcia-Gonzalez et al., 2007). When other conditions are equal, higher temperatures enhance the inactivation of microorganisms (Garcia-Gonzalez et 
Table 1. The survival of Cronobacter spp. in powdered infant formula (inoculated with $3.21 \log _{10} \mathrm{cfu} / \mathrm{g}$ ) following supercritical carbon dioxide treatment under various conditions, as determined by direct plating and plating following sample enrichment $(\mathrm{n}=3)^{1}$

\begin{tabular}{|c|c|c|c|c|c|c|c|}
\hline \multirow[b]{2}{*}{ Pressure (MPa) } & \multirow[b]{2}{*}{ Time (min) } & \multicolumn{2}{|c|}{ Survival at $63^{\circ} \mathrm{C}$} & \multicolumn{2}{|c|}{ Survival at $68^{\circ} \mathrm{C}$} & \multicolumn{2}{|c|}{ Survival at $73^{\circ} \mathrm{C}$} \\
\hline & & Direct plating & Enrichment & Direct plating & Enrichment & Direct plating & Enrichment \\
\hline \multirow{2}{*}{15} & 20 & +++ & +++ & +++ & +++ & --- & -+- \\
\hline & 30 & +++ & +++ & --- & -++ & --- & --- \\
\hline \multirow[t]{2}{*}{20} & 10 & +++ & +++ & +++ & +++ & --- & +++ \\
\hline & 20 & +++ & +++ & +++ & +++ & --- & --- \\
\hline \multirow{2}{*}{25} & 20 & +++ & +++ & +++ & +++ & --- & --- \\
\hline & 30 & +++ & +++ & --- & -+- & --- & --- \\
\hline
\end{tabular}

${ }^{1}+$ : growth; -: no growth. Samples were plated on Chromogenic Enterobacter sakazakii agar (Oxoid, Hampshire, UK).

al., 2007). The effect of temperature on the inactivation of bacteria was more significant than the effect of pressure. The level of Cronobacter spp. in PIF was more rapidly reduced by $\mathrm{SC}-\mathrm{CO}_{2}$ treatment at $73^{\circ} \mathrm{C}$ than at 63 or $68^{\circ} \mathrm{C}$. For example, in samples treated at $10 \mathrm{MPa}$ for $30 \mathrm{~min}$, reduction of Cronobacter spp. was clearly enhanced as the treatment temperatures increased: $1.92 \log _{10} \mathrm{cfu} / \mathrm{g}$ at $63^{\circ} \mathrm{C}<3.76 \log _{10} \mathrm{cfu} / \mathrm{g}$ at $68^{\circ} \mathrm{C}<$ $6.32 \log _{10} \mathrm{cfu} / \mathrm{g}$ at $73^{\circ} \mathrm{C}$. This trend corresponds to the effect of temperature on stimulating the diffusivity of $\mathrm{CO}_{2}$, perhaps through an increase in the fluidity of the cell membrane, which allows for increased diffusion of $\mathrm{CO}_{2}$ into the cell (Lin et al., 1993; Hong et al., 1997; Hong and Pyun, 1999).

\section{Validation of Inactivation Effects in a Low Inoculum Population}

Under certain conditions, SC- $\mathrm{CO}_{2}$ treatment completely inactivated the colony-forming capabilities of Cronobacter spp. However, sublethally injured cells may not be detected in selective media. Cronobacter spp. can survive for long periods in storage because of their high resistance to dry conditions (Breeuwer et al., 2003; Edelson-Mammel et al., 2005), and any surviving cells could recover from damage during rehydrated PIF preparation. If rehydrated infant formula is improperly prepared and left, dramatic growth of Cronobacter spp. could occur. In general, PIF has been reported to be contaminated with low concentrations of Cronobacter spp. (0.36-66 cfu/100 g; Muytjens et al., 1988; Simmons et al., 1989). Thus, it is important to evaluate the effectiveness of $\mathrm{SC}-\mathrm{CO}_{2}$ treatment in samples with low contamination levels. Powdered infant formula was inoculated with low levels of Cronobacter spp. (approximately $3 \log _{10} \mathrm{cfu} / \mathrm{g}$ ) and subjected to $\mathrm{SC}-\mathrm{CO}_{2}$ under various treatment conditions. The samples were then enriched to assess the recovery of cell viability. The survival of Cronobacter spp. in PIF inoculated with a low inoculum following $\mathrm{SC}-\mathrm{CO}_{2}$ is shown in Table 1. After treatment at $68^{\circ} \mathrm{C}$ at $15 \mathrm{MPa}$ for $30 \mathrm{~min}, 68^{\circ} \mathrm{C}$ at $20 \mathrm{MPa}$ for $30 \mathrm{~min}, 68^{\circ} \mathrm{C}$ at $25 \mathrm{MPa}$ for $30 \mathrm{~min}, 73^{\circ} \mathrm{C}$ at $15 \mathrm{MPa}$ for $20 \mathrm{~min}, 73^{\circ} \mathrm{C}$ at $20 \mathrm{MPa}$ for $10 \mathrm{~min}$, and $73^{\circ} \mathrm{C}$ at $25 \mathrm{MPa}$ for $10 \mathrm{~min}$, more than 1 sample presented positive results in the enrichment experiments even though direct plating revealed no colony-forming units. This indicates that the samples were not completely sterilized under these conditions. When PIF was treated with $\mathrm{SC}-\mathrm{CO}_{2}$ at $73^{\circ} \mathrm{C}$ and $20 \mathrm{MPa}$ for 20 min, $25 \mathrm{MPa}$ for $20 \mathrm{~min}, 15 \mathrm{MPa}$ for $30 \mathrm{~min}, 20 \mathrm{MPa}$ for $30 \mathrm{~min}$, and $25 \mathrm{MPa}$ for $30 \mathrm{~min}$, Cronobacter spp. was not detected by either direct plating or enrichment in any sample, indicating complete elimination of the microbe. With regard to efficiency, $\mathrm{SC}-\mathrm{CO}_{2}$ treatment at the lower pressure was more efficient and safe than treatment at the higher pressure. The optimum conditions for elimination of Cronobacter spp. from PIF by SC- $\mathrm{CO}_{2}$ were therefore determined to be $73^{\circ} \mathrm{C}, 20 \mathrm{MPa}$, and $20 \mathrm{~min}$.

\section{Evaluation of PIF Properties Change}

Changes in water activity, $\mathrm{pH}$, and color (Commission International de l'Eclairage and $\Delta \mathrm{E}^{*}$ ) of dehydrated PIF after $\mathrm{SC}-\mathrm{CO}_{2}$ treatment were evaluated. A significant $(P<0.05) 3$-way interaction (temperature $\times$ pressure $\times$ treatment time) was not found in water activity, $\mathrm{pH}$, and color (data not shown). For any given treatment, no statistically significant change in treated PIF was observed $(P>0.05)$.

\section{Applicability of $\mathrm{SC}-\mathrm{CO}_{2}$ to Dehydrate Powdered Infant Formula}

Researchers have investigated several interventions in an effort to reduce the levels of Cronobacter spp. in powdered infant formula, including the use of antimicrobial agents such as monocaprylin, caprylic acid, and 
trans-cinnamaldehyde (Nair et al., 2004; Amalaradjou et al., 2009; Jang and Rhee, 2009); pressure inactivation (Gonzalez et al., 2006; Pina Perez et al., 2007); bacteriophages (Kim et al., 2007a); and gamma radiation (Lee et al., 2006). However, all of these methods have limitations for industrial application. Antimicrobial agents, high-pressure treatments, and bacteriophages are suitable for use in reconstituted infant formula but are not feasible for decontamination of end products in powdered form. Although gamma radiation can be applied to the end products, many consumers have an aversion to gamma-irradiated products. To meet consumer criteria, it is necessary to develop a safe and efficient method for inactivation of Cronobacter spp. that can be applied to the end products.

In the dairy industry, PIF is packaged predominantly in metal containers or sealed plastic bags. Metal containers are usually sealed using the double seaming method. During the first seaming operation, the end of the can body is curled and coverage becomes interlocked. The second seaming operation involves a completely hermetic sealing process using a roll compressed with interlocked layers and the adhesion of sealing compounds inside the end of the cover. During production, the optimal point for the application of $\mathrm{SC}-\mathrm{CO}_{2}$ is between the first and second seaming step; it could permeate the container and sterilize microorganisms with minimal possibility of recontamination or damage to the container. Application of $\mathrm{SC}-\mathrm{CO}_{2}$ before the first step would not be effective because of the possibility of recontamination during seaming, and if $\mathrm{SC}-\mathrm{CO}_{2}$ is applied after seaming, the metal container could be damaged by high pressure. During our experiments, the tubes containing PIF were capped with screw caps during treatment with $\mathrm{SC}-\mathrm{CO}_{2}$, creating conditions close to those described between the first and second steps. Food processers could apply $\mathrm{SC}-\mathrm{CO}_{2}$ to plastic bags immediately before sealing for the above reasons.

The $\mathrm{SC}-\mathrm{CO}_{2}$ system has several advantages for industrial application. Previous methods for control of Cronobacter spp., including addition of antimicrobial agents and radiation, have some drawbacks in that they could not be applied to the end product because they use a method that goes against consumer preference. However, our results show that $\mathrm{SC}-\mathrm{CO}_{2}$ exerts a high bactericidal activity when directly applied to end products in powdered form. Furthermore, $\mathrm{SC}-\mathrm{CO}_{2}$ is chemically inert, nonflammable, nontoxic, and physically safe (Zhang et al., 2006). Because $\mathrm{SC}-\mathrm{CO}_{2}$ is conducted at a relatively low temperature, it would minimize degradation of product quality and other problems encountered during treatment, including corrosion of the metal containers and effusion of hazardous substances from the metal. Because of its advantages, including low critical temperature, stability in chemical and radioactive applications, nontoxicity, and inflammability (Clifford and Williams, 2000), $\mathrm{CO}_{2}$ has been widely used throughout the industry. No $\mathrm{CO}_{2}$ remains on the food products after treatment, thereby eliminating any concern of residual contamination. Decontamination operations are economically advantageous because $\mathrm{CO}_{2}$ is inexpensive and can easily be recovered and reused after processing. Although the $\mathrm{SC}-\mathrm{CO}_{2}$ extraction system used in the present study was somewhat complex and the capacity for each treatment was comparatively small, a $\mathrm{SC}-\mathrm{CO}_{2}$ system to be used purely for microbial inactivation could easily be simplified and expanded, resulting in what could be one of the most effective methods available for elimination of Cronobacter spp. from PIF and other food sources.

In summary, the antimicrobial effect of $\mathrm{SC}-\mathrm{CO}_{2}$ was investigated on Cronobacter spp. in dehydrated PIF. Treatment with $\mathrm{SC}-\mathrm{CO}_{2}$ effectively inactivated Cronobacter spp. without altering the physical properties of the product. The most important benefit of inactivation with $\mathrm{SC}-\mathrm{CO}_{2}$ is its feasibility for direct application to final dehydrated products. Our results indicate that $\mathrm{SC}-\mathrm{CO}_{2}$ treatment could be successfully used to eliminate Cronobacter spp. in the dairy industry and that this method could significantly improve the safety of powdered infant formula.

\section{ACKNOWLEDGMENTS}

This work was supported by the Korea Research Foundation Grant funded by the Korea Government (MOEHRD; KRF-2007-311-F00036). The authors thank the Korea University Food Safety Center (Seoul, South Korea) for providing the equipment and facilities.

\section{REFERENCES}

Amalaradjou, M. A. R., T. A. Hoagland, and K. Venkitanarayanan. 2009. Inactivation of Enterobacter sakazakii in reconstituted infant formula by trans-cinnamaldehyde. Int. J. Food Microbiol. 129:146-149.

Bae, Y. Y., H. J. Lee, S. A. Kim, and M. S. Rhee. 2009. Inactivation of Alicyclobacillus acidoterrestris spores in apple juice by supercritical carbon dioxide. Int. J. Food Microbiol. 136:95-100.

Bar-Oz, B., A. Preminger, O. Peleg, C. Block, and I. Arad. 2001. Enterobacter sakazakii infection in the newborn. Acta Paediatr. 90:356-358.

Barron, J. C., and S. J. Forsythe. 2007. Dry stress and survival time of Enterobacter sakazakii and other Enterobacteriaceae in dehydrated powdered infant formula. J. Food Prot. 70:2111-2117.

Breeuwer, P., A. Lardeau, M. Peterz, and H. M. Joosten. 2003. Desiccation and heat tolerance of Enterobacter sakazakii. J. Appl. Microbiol. 95:967-973.

Burdette, J. H., and C. Santos. 2000. Enterobacter sakazakii brain abscess in the neonate: The importance of neuroradiologic imaging. Pediatr. Radiol. 30:33-34. 
Centers for Disease Control and Prevention. 2002. Enterobacter sakazakii infections associated with the use of powdered infant formula-Tennessee, 2001. JAMA 287:2204-2205.

Choi, Y. M., O. Y. Kim, K. H. Kim, B. C. Kim, and M. S. Rhee. 2009. Combined effect of organic acids and supercritical carbon dioxide treatments against nonpathogenic Escherichia coli, Listeria monocytogenes, Salmonella typhimurium and E. coli O157:H7 in fresh pork. Lett. Appl. Microbiol. 49:510-515.

Clifford, A. A., and J. R. Williams. 2000. Introduction to supercritica fluids and their applications. Page 3 in Supercritical Fluid Methods and Protocols. A. A. Clifford and J. R. Williams, ed. Humana Press Inc., Totowa, NJ.

Dempsey, D. J., and R. R. Thirucote. 1989. Sterilization of medical devices: A review. J. Biomater. Appl. 3:454-523.

Edelson-Mammel, S. G., M. K. Porteous, and R. L. Buchanan. 2005 Survival of Enterobacter sakazakii in a dehydrated powdered infant formula. J. Food Prot. 68:1900-1902.

Enomoto, A., K. Nakamura, M. Hakoda, and N. Amaya. 1997. Letha effect of high-pressure carbon dioxide on a bacterial spore. J Ferment. Bioeng. 83:305-307.

Gallagher, P. G., and W. S. Ball. 1991. Cerebral infarctions due to CNS infection with Enterobacter sakazakii. Pediatr. Radiol. 21:135-136.

Garcia-Gonzalez, L., A. H. Geeraerd, S. Spilimbergo, K. Elst, L. Van Ginneken, J. Debevere, J. F. Van Impe, and F. Devlieghere. 2007. High pressure carbon dioxide inactivation of microorganisms in foods: The past, the present and the future. Int. J. Food Microbiol. $117: 1-28$

González, S., G. J. Flick, F. M. Arritt, D. Holliman, and B. Meadows 2006. Effect of high-pressure processing on strains of Enterobacter sakazakii. J. Food Prot. 69:935-937.

Hong, S. I., W. S. Park, and Y. R. Pyun. 1997. Inactivation of Lactobacillus sp. from kimchi by high pressure carbon dioxide. Lebensm. Wiss. Technol. 30:681-685.

Hong, S. I., and Y. R. Pyun. 1999. Inactivation kinetics of Lactobacillus plantarum by high pressure carbon dioxide. J. Food Sci. 64:728733

Iversen, C., A. Lehner, N. Mullane, E. Bidlas, I. Cleenwerck, J. Marugg, S. Fanning, R. Stephan, and H. Joosten. 2007. The taxonomy of Enterobacter sakazakii: Proposal of a new genus Cronobacter gen. nov. and descriptions of Cronobacter sakazakii comb. nov. Cronobacter sakazakii ssp. sakazakii, comb. nov., Cronobacter sakazakii ssp. malonaticus ssp. nov., Cronobacter turicensis sp. nov., Cronobacter muytjensii sp. nov., Cronobacter dublinensis sp. nov. and Cronobacter genomospecies 1. BMC Evol. Biol. 7:64.

Jang, H. I., and M. S. Rhee. 2009. Inhibitory effect of caprylic acid and mild heat on Cronobacter spp. (Enterobacter sakazakii) in reconstituted infant formula and determination of injury by flow cytometry. Int. J. Food Microbiol. 133:113-120.

Kamihira, M., M. Taniguchi, and T. Kobayashi. 1987. Sterilization of microorganisms with supercritical carbon dioxide. Agric. Biol. Chem. 51:407-412.

Kim, K. P., J. Klumpp, and M. J. Loessner. 2007a. Enterobacter sakazaki bacteriophages can prevent bacterial growth in reconstituted infant formula. Int. J. Food Microbiol. 115:195-203.
Kim, S. R., M. S. Rhee, B. C. Kim, H. Lee, and K. H. Kim. 2007b. Modeling of the inactivation of Salmonella typhimurium by supercritical carbon dioxide in physiological saline and phosphatebuffered saline. J. Microbiol. Methods 70:132-141.

König, C., K. Ruffieux, E. Wintermantel, and J. Blaser. 1997. Autosterilization of biodegradable implants by injection molding process. J. Biomed. Mater. Res. 38:115-119.

Lee, J. W., S. H. Oh, J. H. Kim, H. S. Yook, and M. W. Byun. 2006. Gamma radiation sensitivity of Enterobacter sakazakii in dehydrated powdered infant formula. J. Food Prot. 69:14341437.

Lin, H., Z. Yang, and L. Chen. 1993. Inactivation of Leuconostoc dextranicum with carbon dioxide under pressure. Chem. Eng. J. $52: 29-34$.

Mazzoni, A. M., R. R. Sharma, A. L. I. Demirci, and G. R. Ziegler 2001. Supercritical carbon dioxide treatment to inactivate aerobic microorganisms on alfalfa seeds. J. Food Saf. 21:215-223.

Muytjens, H. L., H. Roelofs-Willemse, and G. H. Jaspar. 1988. Quality of powdered substitutes for breast milk with regard to members of the family Enterobacteriaceae. J. Clin. Microbiol. 26:743-746.

Muytjens, H. L., H. C. Zanen, H. J. Sonderkamp, L. A. Kollee, I. K. Wachsmuth, and J. J. Farmer. 1983. Analysis of eight cases of neonatal meningitis and sepsis due to Enterobacter sakazakii. J. Clin. Microbiol. 18:115-120.

Nair, M. K. M., J. Joy, and K. S. Venkitanarayanan. 2004. Inactivation of Enterobacter sakazakii in reconstituted infant formula by monocaprylin. J. Food Prot. 67:2815-2819.

Nair, P. D. 1995. Currently practised sterilization methods-Some inadvertent consequences. J. Biomater. Appl. 10:121-135.

Pina Pérez, M. C., D. Rodrigo Aliaga, D. Saucedo Reyes, and A. Martinez Lopez. 2007. Pressure inactivation kinetics of Enterobacter sakazakii in infant formula milk. J. Food Prot. 70:2281-2289.

Simmons, B. P., M. S. Gelfand, M. Haas, L. Metts, and J. Ferguson. 1989. Enterobacter sakazakii infections in neonates associated with intrinsic contamination of a powdered infant formula. Infect. Control Hosp. Epidemiol. 10:398-401.

Spilimbergo, S., and A. Bertucco. 2003. Non-thermal bacterial inactivation with dense $\mathrm{CO}_{2}$. Biotechnol. Bioeng. 84:627-638.

Spilimbergo, S., F. Dehghani, A. Bertucco, and N. R. Foster. 2003. Inactivation of bacteria and spores by pulse electric field and high pressure $\mathrm{CO}_{2}$ at low temperature. Biotechnol. Bioeng. 82:118125.

van Acker, J., F. De Smet, G. Muyldermans, A. Bougatef, A. Naessens, and S. Lauwers. 2001. Outbreak of necrotizing enterocolitis associated with Enterobacter sakazakii in powdered milk formula. J. Clin. Microbiol. 39:293-297.

Weir, E. 2002. Powdered infant formula and fatal infection with Enterobacter sakazakii. Can. Med. Assoc. J. 166:1570.

Zhang, J., S. Burrows, C. Gleason, M. A. Matthews, M. J. Drews, M Laberge, and Y. H. An. 2006. Sterilizing Bacillus pumilus spores using supercritical carbon dioxide. J. Microbiol. Methods 66:479485. 